\title{
Kommentaar artiklile "Hüperventilatsiooni ilmingud rituaalsetes tantsudes"
}

Lea Maipuu

Käesolevas uurimustöös on püstitatud hüpotees, et nganassaani rituaalse tantsu ja musitseerimisega kaasnevad neuropsühholoogilised sümptomid on seostatavad hüperventilatsiooni ja hüpokapnia ehk sügava forsseeritud hingamise ja madala süsihappegaasiga veres ning selle abil tekitatakse transiseisund.

Praktilises meditsiinis kasutatakse hingamise iseloomustamisel järgmisi üheselt mõistetavaid termineid:

- kopsude ventilatsioon ehk kopsude tuulutus ehk minutimaht - s.o hingetõmmete sügavusest ja sagedusest sõltuv kopse läbiv õhuhulk ajaühikus (normaalselt 7 1/min);

- hüperventilatsioon - suurenenud hingamine ehk sügav ja kiire hingamine;

- hüpoventilatsioon - vähenenud kopsuventilatsioon;

- hüperkapnia - süsihappegaasi liigsus veres;

- hüpokapnia - süsihappegaasi vaegus veres;

- hüperoksia - hapniku liigsus veres;

- hüpoksia - hapniku vaegus veres;

- eupnoe - normaalne hingamine;

- apnoe - hingamise puudumine;

- tahhüpnoe - kiire hingamine (tavaliselt kompensatsioon $\mathrm{O}_{2}$ tarbimise kasvule või hapniku kahanemisele veres jne).

Looduses on hingamine aeroobsetele elusorganismidele energiat tootva ainevahetuse eeltingimus. Sissehingatava hapniku abil, mis vereringe poolt transporditakse kudedeni, moodustub rakkudes glükolüüsi teel keemiline ühend adenosiintrifosfaat (ATP). See ongi materiaalne energiat kandev molekul, mida aeroobsed elusrakud kasutavad ettenähtud funktsioonide täitmiseks. Väljahingatav õhk sisaldab orgaaniliste ühendite ainevahetuse lõpp-produk- 
ti - vett ja süsihappegaasi. Kui vee elimineerimiseks on organismil ka muid teid, siis süsihappegaasi eritumine saab toimuda vaid kopsude kaudu. Normaalselt hoitakse arteriaalses veres hapnik ja süsihappegaas püsivalt ühtlases kontsentratsioonis vaatamata ainevahetuse intensiivistumisele või aeglustumisele. Vastsündinu hingabki kaks-kolm korda täiskasvanust sagedamini seepärast, et tema hapnikutarve ehk ainevahetus on kaks korda kiirem. On loogiline, et inimene ei saa reguleerida oma valitud hingamisrütmiga ainevahetust, vaid ainevahetus on ülim hingamisrütmi reguleerija.

Mehaanikalt on hingamine aktiivse lihastöö tulemusel tekkiv õhu kopsu "imemine" ja seejärel diafragma lõtvumisel, rindkere raskusjõul ja hingamislihaste jõuga peaaegu sama õhu hulga välja voolutamine. Kopsudel on omadus kokku tõmbuda ning nende avamiseks kulutatakse teatud hulk energiat.

Rakendusmeditsiinis käsitletaksegi hingamist kui hapniku ja süsihappegaasi gaasivahetuse protsessi. Vastavate eksperimentaaluuringutega on võimalik jälgida kõiki hingamises osalevate süsteemide seisundit. Mõõdetakse hingamistorude ventilatoorset funktsiooni, alveoolide gaasivahetusprotsessi, jälgitakse vereringet, mille ülesandeks on hemoglobiini kui hapnikukandja transportimine lõpptarbijani ja sealt süsihappegaasi sisaldava karboksühemoglobiini tagasi transportimine kopsu, mõõdetakse hemoglobiini, oksüja karboksühemoglobiini hulka veres jne. Kopsu kapillaaridest difundeerub süsihappegaas vabalt väljahingatavasse õhku ning viiakse tagasi atmosfääri. Hingamise parameetrite järgi hindab klinitsist kaudselt ka organismi ainevahetuse protsesse.

Hingamise rütmi ja sügavuse reguleerijaiks on kesknärvisüsteemis asuv hingamiskeskus. Tänapäeval on selgunud, et seal esineb kahte tüüpi närvirakke: ühed on aktiivsed peamiselt sissehingamise faasis (inspiratoorsed neuronid), teised saadavad välja impulsse väljahingamisfaasis (ekspiratoorsed neuronid). Neid neuroneid on praeguseks ajaks leitud kuut liiki ja nende tööd, seega hingamist reguleerivad:

- veregaasid ja vere happealustasakaal (vesinikioonide kontsentratsioon) - see on hingamise keemiline kontroll;

- kopsust saabuvad venitusimpulsid;

- refleksid hingamislihastelt;

- mittespetsiifilised hingamisstiimulid (temperatuur, valu, ärevus, paanika, seks, mitmesugused hormoonid, nagu adrenaliin füüsilise töö ja psüühilise erutuse korral, progesteroon raseduse ajal) jne.

Joonisel 1 on näidatud gaaside osa atmosfääris, väljahingatavas õhus, kopsus ehk alveolaarses õhus, venoosses (must) ja arteriaalses veres (valge) ning kudedes. $\mathrm{P}_{\mathrm{O}_{2}}$ on hapniku osarõhk, $\mathrm{P}_{\mathrm{CO}_{2}}$ - süsihappegaasi osarõhk, $\mathrm{P}_{\mathrm{N}_{2}}$ - 


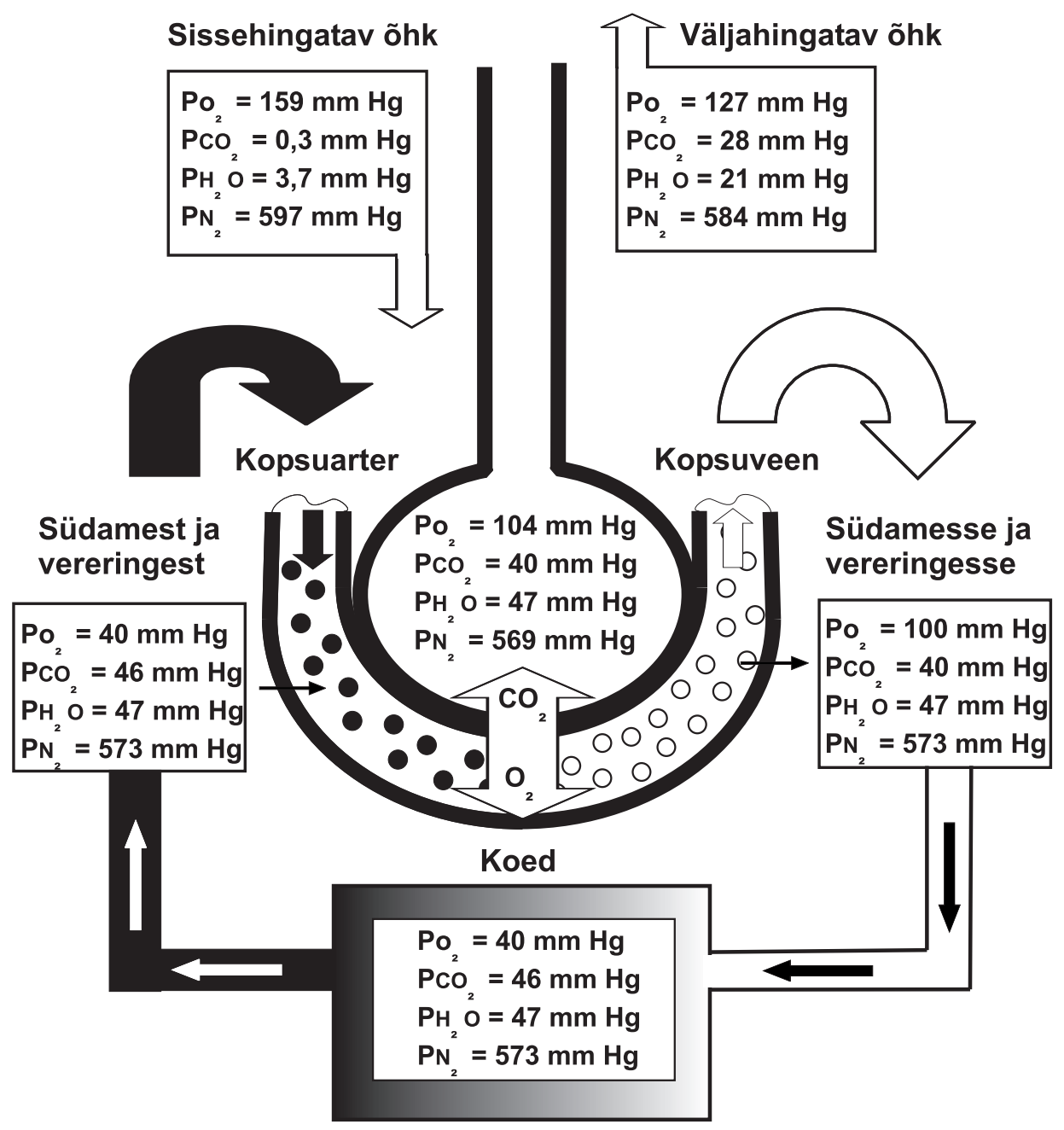

Joonis 1. Gaaside osa atmosfääris, väljahingatavas õhus, kopsus ehk alveolaarses õhus, venoosses ja arteriaalses veres ning kudedes.

lämmastiku osarõhk, $\mathrm{P}_{\mathrm{H}_{2} \mathrm{O}}$ - veeauru osarõhk. Skeemil näidatud osarõhu väärtused on keskmised normväärtused. Muutus igas lülis nihutab hingamise rütmi ja sügavust.

Kuigi teame, et elusolenditel esineb kaks automaatset vitaalset rütmi südamerütm ja tsentraalne hingamisrütm -, ei ole siiani selge, miks hingamise automatismile lisandub inimesel võime või vajadus tahtlikult või tahtmatult hingamisrütmi muuta. Miks on see tähtis ja mis seda juhib, pole täpselt teada. Siit teadlaste suur huvi ja kohati ka spekulatsioonid hüperventilatsiooni teemadel. 
Sisse- ja väljahingamise tsüklid on rahuolekus enamasti ajaliselt jaotunud suhtes 1:3 (imikutel 1:1). Hingamise kiirenemine toimub tavaliselt väljahingamistsükli lühenemise arvel. Olukorda, kus väljahingamisfaas oleks sissehingamisest lühem, me normaalselt ei näe. Raske hingamispuudulikkuse ravis kopsude kunstliku hingamise tingimustes kasutatakse harvadel juhtudel ka sellist hingamismudelit.

Hüperventilatsioon viib terve kopsu korral alati hüpokapniale, sest süsihappegaasi vahetus toimub kopsus (alveoolis) difusiooni teel kontsentratsioonide ühtlustumise põhimõttel väga kiiresti. Et atmosfääris süsihappegaasi peaaegu ei ole $(0,3 \mathrm{~mm} \mathrm{Hg})$ ja veres on see $\sim 40 \mathrm{~mm} \mathrm{Hg}$, toimub paratamatult iga hingamisega gaasivahetus. Haigusliku ilminguna esineb hüperventilatsioon kompensatsioonina ${ }^{1}$ kopsu- või südamehaiguste, ainevahetushäirete (atsidoos), palaviku, ajukahjustuse, psühhiaatriliste haiguste jt patoloogiate korral. Füsioloogilistest põhjustest viib hüperventilatsioonile stress, valu, hirm, seks jne. Hüperventilatsiooni ja/või hüpokapniaga kaasnevad sümptomid kestavad tavaliselt 20-30 minutit. Nendeks sümptomiteks on ärevuse, erutuse ja pinge tõus, õhupuuduse tunne, südamekloppimine, pearinglus, tasakaaluhäired, jäsemete tuimus, sipelgatejooksu tunne, rindkere täitumine, tundlikkus, valu, peavalu, lihastõmblused, higistamine, nägemishäired (nägemise hägunemine või tunneli visioon), mälu ja teadvuse seisundi häired kuni teadvuse kaotuseni. Lühiaegne hüperventilatsioon tekitab disponeeritud, st vastuvõtlikel või vastavalt häälestatud indiviididel ärevust, kerget eufooriat, muudab keha taju ja tunnetust, mis väljendub ärritunud olekus ehk düsfoorias. Pikaajaline hüperventilatsioon võib esile kutsuda sügavamaid muutusi teadvuse seisundis. On parameditsiinilisi psühhoterapeutilisi võtteid, millega saavutatakse transitaoline seisund hüperventilatsiooni kasutades.

Praktilise meditsiini seisukohalt on hüperventilatsiooniga kaasneval hüpokapnial negatiivsed regulatoorsed toimed organismile. Hüpokapnia põhjustab organismis vereringe muutusi, respiratoorset alkaloosi koos elektrolüütide nihkega ja neuromuskulaarse ärritatavuse kasvu (lihaste tetaaniline sündroom, paresteesiad), naha kahvatust ja südame pärgarterite ahenemist. Arteriaalse vere süsihappegaasi osarõhk $\left(\mathrm{Pa}\left(\mathrm{CO}_{2}\right)\right)$ on tähtis ajuvereringe regulaator ning $\mathrm{Pa}\left(\mathrm{CO}_{2}\right)$ muutused mõjutavad aju verevoolu ja selle kaudu aju hapnikuga varustatust. Arvatakse, et kesknärvisüsteemi mõjutusest tulenevadki hüperventilatsiooni närvisüsteemi kliinilised ilmingud. Intensiivravis ja anestesioloogias monitooritakse patsientidel pidevalt süsihappegaasi veres ja väljahingatavas õhus, eriti kopsude kunstliku ventilatsiooni korral, et mitte kahjustada kesknärvisüsteemi. Tuleb mainida, et laboratoorselt fikseeritud hüpokapniaga patsientidel pole siinkirjutaja mingeid transiilmin- 
gud märganud. Samas aga on uurijad leidnud seoseid hüpokapnia ja mitmesuguste psühholoogiliste ning patopsühholoogiliste protsesside vahel. Ilmselt peab siin toimima veel mingi faktor. Saksa füsioloogid Pavel Terekhin ja Clemens Foster (2006) on läbi viinud huvitava uuringu vabatahtlikel, kes teadlikult hüperventileerides tekitasid endale hüpokapnia. Uuriti katsealuste ajukoore reaktiivsust (s.o verevoolu muutusi) valule, motoorsele tegevusele ja rahuolekule nii normaalsetes kui ka hüperventilatsiooni tingimustes. Katsealused hingasid kiirelt ja sügavalt seni, kuni $\mathrm{CO}_{2}$ väljahingatavas õhus (Pet $\left(\mathrm{CO}_{2}\right)$ ) oli langenud vahemikku 23-28 $\mathrm{mm} \mathrm{Hg}$ (hüpokapnia) ning uurijad jälgisid funktsionaalse magnetresonantstomograafi abil ajuverevoolu muutusi. Ajukoore eri piirkondades ilmnesid hapnikutaseme ja ajustruktuuride aktiivsuse erinevused vastavalt sellele, kas oli tegemist hüpokapniaga või normokapniaga ning milline ärritaja toimis. Hüpokapnia korral tajusid uuritavad valu nõrgemini ja artikli autoritel on hüpotees, et valuga kaasnev hüperventilatsioon tekitab adrenergilise ja endogeense valupärssivate opioidsüsteemide stimuleerimise ning valu tajumise vähenemise. Samas oli verevoolude muutus motoorsele ärritusele hoopis teise lokalisatsiooni ja mustriga.

Transiseisundi uurimine ja selle neuropsühholoogilised alused on siiani teaduslikult selgitamata eeskätt riituste pühaduse ja salastatuse tõttu. Jaapani neurofüsioloogid Norie Kawai, Manabu Honda, Satoshi Nakamura jt (2001) leidsid võimaluse uurida Indoneesias Bali saarel Calonarangi riituses osalejate vereanalüüse, seda nii transsi langenuil kui ka mehaaniliselt kaasa liikuvatel inimestel. Analüüsiti neuroaktiivseid aineid, nagu adrenaliini, noradrenaliini, dopamiini, nende ainete metaboliite ning neuropeptiide (adrenokortikotroopset hormooni, endorfiini jne). Uuring näitas, et nimetatud ainete kontsentratsioon veres oli transsi langenuil oluliselt kõrgem kui teistel. Samas olid enne riitust võetud proovid mõlemal grupil sarnased. Uurijad järeldasid, et nimetatud neuroaktiivsed kesknärvisüsteemi mõjutavad ained avaldavad märkimisväärset toimet teadvusele, mälule, valutundlikkusele ja käitumisele. Nagu öeldud, on samad ained ka hingamiskeskuse stimulandid.

Teadlased on uurinud hüperventilatsiooni tähtsust ka mitmesuguste füsioloogiliste psühhoemotsionaalsete seisundite ja tegevuste (seks, orgasm, masturbatsioon, ärevus, paanika, hirm, jne) korral. Väljendunud hüperventilatsiooni suguühte ajal seletatakse emotsionaalse tundetulva, füüsilise pingutuse ja erutuse kombineeritud toimega kesknärvisüsteemile. Ajukoore verevarustuse vähenemine väljendub uuemates ajukoore osades (neokorteksis) rohkem kui fülogeneetiliselt vanemates subkortikaalsetes osades. Neokorteksi pidurdav või kontrolliv funktsioon nõrgeneb ning subkortikaalne struk- 
tuur (limbiline süsteem) hakkab domineerima. Teadlased on esitanud hüpoteesi, et teadvusseisundi muutused hüperventilatsiooni korral võivadki olla tingitud kortikaalse ja subkortikaalse regulatsiooni muutustest.

Paljudes teaduslikes teooriates ja empiirilistes töödes seostatakse patoloogilist ärevust ja paanikat hüperventilatsiooniga. Tahtliku hüperventilatsiooniga võib haige haiguslikke ilminguid ise esile kutsuda ning siis on see ka diagnostiline vahend. Samas kasutatakse aga hingamistreeninguid (sh teadlikku hüperventilatsiooni) ka samade psühhiaatriliste häirete raviks.

Käesoleva uurimustöö puhul on autor käsitlenud hüperventilatsiooni küll suhteliselt lihtsustatult, kuid põhimõtteliselt õigesti. Hääleaparaadi töö analüüsi osas ei suuda siinkirjutaja kaasa rääkida. Samas aga usub ta, et laulmise ja heliaparaadi töö seost veregaaside muutustega on vastava eriala spetsialistid ilmselt kaasaegsel tasemel juba monitoorinud. Rahuolekus tehtud hingamistsükli analüüsimisel on kasutatud väljendit õhuvoolu oklusioon ehk sulgus. Kui hingaja häälepaelu ei sulge (see toimub vaid köha, kõnelemise, laulmise punnestamise korral), oleks täpsem väljend ilmselt hingamise füsioloogias kasutatav õhuvoolu katkemine. Füsioloogias nimetatakse seda ka kolmandaks hingamisfaasiks. Raskesti mõistetav on aga lause: Süsinikdioksiidi langus käivitab teatud patofüsioloogilised protsessid veres ja ajus, mis on hüpokapnia eelsoodumuseks. Veel täpsustuseks: hingamistsüklite vahekord on füsioloogiliselt ära määratud sellega, et mida kiiremini hingatakse, seda lühemaks jääb ekspiirium.

Uurimistöö autori hüpotees, et tants (motoorne tegevus), laulmise ja/või hingamise tehnika, rituaalis osalejate psüühiline eelhäälestus ning kultuuriline taust võivad olla transi seisundi esilekutsujad, on maailmas ka teiste teadlaste poolt tunnustatud teooria. Jääb üle vaid oodata neurofüsioloogide kinnitust sellele.

\section{Kommentaar}

${ }^{1}$ Meditsiinis tähendab kompensatsioon nõrga või ülekoormatud elundi talitluse reguleerimist organismisiseste kohastumuslike muutuste varal. 


\section{Kirjandus}

Nore Kawai \& Honda, Manabu \& Nakamura, Satoshi \& Samatra, Purwa \& Sukardika, Ketut \& Nakatani, Yoji \& Shimojo, Nobuhiro \& Oohashi, Tsutomu 2001. Catecholamines and opioid peptides increase in plasma in humans during possession trances. Cognitive Neuroscience and Neuropsyhology 12: 16, lk 3419-3423.

Terekhin, Pavel \& Foster, Clemens 2006. Hypocapnia related changes in pain-induced brain activation as measured by functional MRT. Neuroscience Letters 400: 1, lk 110114.

\section{Soovitavat lugemist}

Schmidt, Robert Franz \& Thews, Gerhard 1997. Inimese füsioloogia. Tartu: Tartu Ülikool.

Laffey, John G. \& Kavanagh, Brian P. 2002. Hypocapnia. The New England journal of medicine 347: 1, lk 43-53.

Ojamaa, Triinu \& Aru, Jaak 2005. Can Hyperventilation be a Trance Mechanism in Nganasan Ritual Dance Accompaniment? Proceedings of the Conference on Interdisciplinary Musicology (CIM05) = Actes du Colloque interdisciplinaire de musicologie (CIM05): Montréal (Québec) Canada, 10-12/03/2005. CD (vt ka www.oicm.umontreal.ca/cim05/cim05_articles/OJAMAA_T_CIM05.pdf - 20. oktoober 2006).

Paulev, Poul-Eric 1999-2000. Control Of Respiration: High Altitude. Textbook in Medical Physiology and Pathophysiology. Copenhagen Medical Publishers (http:// forlag.fadl.dk/sample/paulev/book/chapter16/Chapter\%2016.htm - 13. oktoober 2006).

Bogovski, Pavel \& Kull Rein (koost \& toim) 1996. Meditsiinisõnastik: Eestikeelsed terminid koos seletuste ning ladina, inglise ja soome vastetega. Tallinn: Medicina.

Parkes, Michael J. 2005. Breath-holding and its Breakpoint. Experimental Physiology 91: 1, lk 1-15 (http://ep.physoc.org/cgi/content/full/91/1/1 - 13. oktoober 2006).

Passie, Torsten \& Hartmann, Uwe \& Schneider, Udo \& Emrich, Hinderk M. 2003. On the Function of Groaning and Hyperventilation during Sexual Intercourse: Intensification of Sexual Experience by Altering Brain Metabolism through Hypocapnia. Medical Hypothesis 60: 5, lk 660-663.

Meuret, Alecia E. \& Ritz, Thomas \& Wilhelm, Frank H. \& Roth, Walton T. 2005. Voluntary Hyperventilation in the Treatment of Panic Disorder - Function of Hyperventilation, their Implications for Breathing Training, and Recommendations for Standardization. Clinical Psychology Review 25, lk 285-306. 


\title{
Summary \\ Comments to the article Manifestation of hyperventilation in ritual dances
}

\author{
Lea Maipuu
}

In applied medicine, respiration is viewed as the chemical process of gas exchange of oxygen and carbon dioxide. Corresponding experimental studies have enabled to observe the condition of all systems involved in respiration. In relaxation state, the cycles of inhalation and exhalation generally follow the temporal ratio 1:3 (1:1 for infants). The acceleration of breathing rate usually occurs on account of the shortening of exhalation cycle. The situation in which the exhalation phase is longer than the inhalation phase cannot be seen in normal circumstances. In the treatment of acute respiratory failure, this pattern of breathing is in rare cases used together with artificial pulmonary respiration. Hyperventilation always leads to hypocapnia of a healthy lung, since the exchange of carbon dioxide in alveolus occurs very rapidly by means of diffusion on the principle of redistribution of concentrations. From the viewpoint of medical practices, hypocapnia resulting from hyperventilation has a negative regulatory effect on humans. Scientists have explored the role of hyperventilation in various physiological psychoemotional conditions and activities. Various scientific theories and empirical studies link pathological anxiety and panic with hyperventilation. A patient may deliberately use hyperventilation to bring on clinical symptoms and in this case it is used as a diagnostic tool. At the same time, respiration training (including deliberate hyperventilation) is used for the same psychiatric disorders. In this study, the author's approach to hyperventilation is somewhat overgeneralised but is accurate in principle. The hypothesis posed by the author of the article, arguing that dancing (a motor activity), the technique of singing and/or breathing, the psychological disposition of participants of the ritual and the cultural context may evoke the state of trance, is a theory generally recognised also by other scholars. 